ISSN 1112-9867

Available online at

http://www.jfas.info

\title{
OPTIMIZATION OF MICROGRIDS BASED ON CONTROLLER DESIGNING FOR ISLANDED OPERATION
}

\author{
F. Arefi ${ }^{1, *}$, H. S. Unesi ${ }^{2}$ and S. Ruzbehi ${ }^{3}$ \\ ${ }^{1}$ Department of Electrical Engineering, Hamedan Branch, Islamic Azad University, Hamedan, \\ Iran \\ ${ }^{2}$ Department of Electrical Engineering, Sanandaj Branch, Islamic Azad University, \\ Kordestan, Iran \\ ${ }^{3}$ Department of Electrical Engineering, Hamedan Branch, Islamic Azad University, Hamedan, \\ Iran
}

Published online: 05 June 2016

\begin{abstract}
The power quality of microgrid during islanded operation is strongly related with the controller performance of DGs. Therefore a new optimal control strategy for distributed generation based inverter to connect to the generalized microgrid is proposed. This work shows developing optimal control algorithms for the DG interface that guarantee stable and high power quality injection under the occurrence of network disturbances. In this paper, two typical distributed generation (DG) units are connected in parallel to configuration the Microgrid. One of DG units has voltage- frequency (VF) controller loop and other has active-reactive (PQ) power controller loop that based on the conventional PI regulators. Through simulation in Matlab by selecting appropriate genetic algorithm is designed to tune the parameters $\mathrm{Kp}_{\mathrm{i}}$ and $\mathrm{Ki}_{\mathrm{i}}$ of the PI controllers, the performance of the system to demonstrate the effectiveness of the proposed methodology.
\end{abstract}

Keywords: Optimization; Microgrid; Controller; Distributed Generation; Island.

Author Correspondence, e-mail: farzad_are2000@yahoo.com

doi: $\underline{\text { http://dx.doi.org/10.4314/jfas.8vi2s.15 }}$ 


\section{INTRODUCTION}

A microgrid has on-site power generation and operates as a single controllable in parallel to the main grid. Microgrid can enable easy penetration of renewable energy sources, reduce greenhouse gas emissions, reduce the stress on the grid, lower the energy bills, create green jobs, and improve the critical reliability and security of the electric grid. It can also be a part of potential solution for greenhouse gas goals.

Microgrids are almost $85 \%$ efficient as they have very less transmission losses and use the surplus heat to warm or cool buildings. During power outage or disturbance, Microgrids can island themselves and retain power availability, avoiding blackouts and lost productivity. With the power source located on-site, Microgrids are less vulnerable to cyber attacks on the grid since they do not rely on transmission lines and have the security of redundant systems. Microgrids have the ability to address the world's energy crisis by reducing the power load on our utility grid; reducing energy security risks and providing clean energy resources that are more reliable and economical.

The microgrid standards of operation and control are significantly different from that of the power grid [1]. Communication-based control of a microgrid system relies on sharing control information among different generators. This technique requires a centralized microgrid controller, which receives the terminal information of each inverter and loads to dispatch the inverter units at different load conditions [2]. There are many drawbacks in communicationbased approach. Non-communication based control relies on the ability of individual DG units to regulate the output voltage and frequency while sharing the active and reactive power demands. Signal injection is used as a decentralized power sharing mechanism in paralleled inverters system [3]. However, the complexity of signal injection and the robustness of measuring output power variations caused by the injected signal make this scheme far from being practical. In the context of micro-gird control, few results have been reported. In [4], [5] - [6], a static droop controller is utilized for power sharing. In [7], an enhanced droop control featuring a transient droop performance is proposed. To improve the active and reactive power decoupling performance, improved droop controllers with virtual output impedance are reported [8]. To account for nonlinear load sharing, harmonic droop controller is reported in [9].In [10] a new control scheme for DGs using a current controlled voltage source inverter (VSI) was proposed. Besides conditioning the power fed by the DG, power quality problems were mitigated. Microgrid can operate in two modes, islanded mode and grid connected mode. Islanded mode is, when during the disturbances; the microgrid disconnects itself from 
the main grid and operates autonomously maintaining high quality of service, without harming the transmission grid's integrity. In the islanded mode, due to unavailability of the utility grid, two additional requirements must be fulfilled: Power balance between generation and demand of the system and control of voltage amplitude and frequency of the installation. Due to the non-controllable nature of renewable energy sources, controllable micro sources such as engine generator, fuel cell and energy storage system are responsible for ensuring power balance by absorbing or injecting the power difference between renewable generation and local load demand. When there is sufficient energy, the energy management system has to control the output power of controllable micro sources to maintain the frequency and voltage of the distributed power system. In the grid connected mode, the microgrid is connected to the main grid and enables bidirectional power flow [11], and power balance between generation and demand as well as the frequency and voltage of the distributed power system are guaranteed by the utility grid. Thus, the distributed power system can operate as a power generator or as a power load, and filters active power transferring between the distributed power system and the main distribution system. The microgrid can optimize the aggregate distribution system by coordinating the generation and load to increase the robustness and reliability of the system, in both the modes of operation [12]. Island detection of DG is considered one of the most imprtant aspects regarding microgrid operation.most of the islanding detection methods, previously developed focused on DGs that operation at unity power factor. With the increasing penetration and reliance of the distributin systems on DGs, new interface control strategies are being proposed for inverter based DGs due to their flexibility. In [13] the interface control was designed to supply active power and improve the power factor at the point of interconnection of the DG.In [14] the proposed interface control takes into account DG islanding protection by proposing a control scheme that supplies active power improves power factor and provides active islanding detection. In [15] the interface control was designed to provide voltage support by supplying active and reactive power, especially during the peak load time. The reduction of unbalance in voltage and harmonics using the interface control of DG was proposed in [16]. In [17] control techniques of inverter based DGs that focus on improving the power quality ensuring continuity of supply were discussed. In [18] proposed method for microgrid operation is the master-slave approach. The scheme of microgrid operation combines a voltage controlled inverter and current controlled inverters. In addition, in the past decade, many researchers have attempted to combine conventional PID controllers with fuzzy logic to improve controller performance [19, 
20].large controllers for the inverter based DGs are presented in reference [21]. A small-signal state-space model of autonomous operation of inverter-based microgrid is presented [22]. Each distributed generation inverter has an outer power loop, based on the droop control, to share the real and reactive powers with other distributed generations.

In this paper, the ultimate aim is to provide conditions for stable operation of isolated power systems. This requires a satisfactory control of active and reactive power flow in the system. In other words the balance for generation and demand and consequently voltage and frequency in the system should be kept constant. This work is concerned with the generation control in microgrid systems consisting of inverter interfaced generation systems. Two DGs units considerate that one of them included $V F$ controller and other included controller scheme $P Q$. In paper used from genetic algorithm for optimized coefficents two types controller scheme based on the conventional PI regulators.

This paper is organized as follow; basic structure of VSI controller in Section 2, Control Strategies for Microgrid during Islanded Mode in Section 3, Solution Methodology in Section 4, Configuration of a Test System in Section 5, application study and numerical results in Section 6 and the conclusion in Section 7.

\section{BASIC STRUCTURE OF THE VSI CONTROLLER}

The VSI controller works like an exciter and governor synchronous machine, controlling the voltage and frequency. The VSI acts as a voltage source, with the magnitude and frequency of the output voltage controlled through droops. In a standalone AC system, the VSI acts as voltage source with magnitude and frequency of the output voltage set according to its active and reactive power output. In terms of standalone AC system operation, this control principle allows the VSI to react to system disturbances (e.g., load or generation changes) based on information available at its terminals $[23,24]$. The entire control of the inverter is performed in the stationary $d-q$ reference frame and is essentially vector control. The transformation from the physical $a b c$ reference frame to the stationary $d q n$ reference frame is performed by the Clarke transformation and is described by the following equations (1).

$$
\left[\begin{array}{l}
f_{d} \\
f_{q} \\
f_{n}
\end{array}\right]=\frac{2}{3}\left[\begin{array}{ccc}
0 & \frac{-\sqrt{3}}{2} & \frac{\sqrt{3}}{2} \\
1 & \frac{-1}{2} & \frac{-1}{2} \\
\frac{1}{\sqrt{2}} & \frac{1}{\sqrt{2}} & \frac{1}{\sqrt{2}}
\end{array}\right]\left[\begin{array}{l}
f_{a} \\
f_{b} \\
f_{c}
\end{array}\right]
$$


In these equations, the quantity $f$ denotes a physical quantity, such as a voltage or a current. For a six-pulse VSI, the inverter output voltage space vector can take any of seven positions in the plane specified by the $q d$ - coordinates. These are shown in Fig.1as the vectors 0-6.

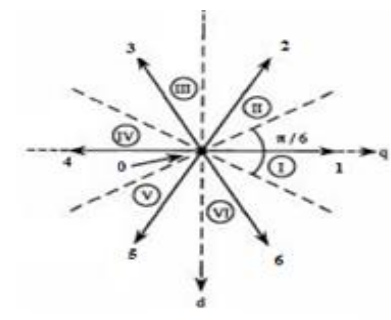

(a)

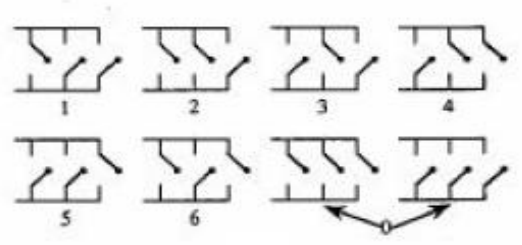

(b)

Fig.1. a) Inverter output voltage vectors; b) Inverter switch positions [7]

The magnitude of $\mathrm{V}_{\mathrm{m}}$ is:

$V_{m}=\sqrt{V_{d}^{2}+V_{q}^{2}}$

The angle of ${ }^{\phi}$ with respect to $q$ axis is:

$\phi=\tan ^{-1}\left(\frac{V_{q}}{V_{d}}\right)$

\section{CONTROL STRATEGIES FOR MICROGRID DURING ISLANDED MODE}

Three control techniques for interfacing DGs to the distribution system were reviewed in this section. The DG is operated either to control the DG output current, active power, output frequency and voltage at the common coupling or active and reactive output power of the DG. In this work, we used from two models PQ and VF controllers.

\section{A. constant power (PQ) controlled inverter}

The interface control shown in Fig. 2 was designed to supply constant active and reactive power. The output active and reactive powers of the DG are measured and are compared to reference values. The errors are applied to a PI controller to determine $I_{\text {dref }}$ and $I_{\text {qref }}$ of the inverter output current. These values are then compared with the inverter $I_{d}$ and $I_{q}$ current components and the error is passed to another PI controller. Similarly the outputs of the PI controllers $\left(\mathrm{V}_{\text {dref }}\right.$ and $\left.\mathrm{V}_{\text {qref }}\right)$ are then further processed as shown in Fig 1 to obtain the modulation signal amplitude and phase angle. Active and reactive power flowing through a line can be given as [25]: 


$$
\begin{aligned}
& P=\frac{3}{2}\left(v_{d} d_{d}+v_{q} i_{q}\right) \\
& Q=\frac{3}{2}\left(v_{q} q_{d}-v_{d} i_{q}\right)
\end{aligned}
$$

The vector relationship between the inverter voltage (V) and the local microgrid voltage along with the inductor's reactance and resistance determines the flow of active and reactive power from the power system to the microgrid. The corresponding mathematical relations for $\mathrm{P} \& \mathrm{Q}$ magnitudes are the following:

$$
\begin{aligned}
& P=\frac{V_{1}}{R^{2}+X^{2}}\left(R\left(V_{1}-V_{2} \cos \delta\right)+X V_{2} \sin \delta\right) \\
& Q=\frac{V_{1}}{R^{2}+X^{2}}\left(-R V_{2} \sin \delta+X\left(V_{1}-V_{2} \cos \delta\right)\right)
\end{aligned}
$$

Where $\mathrm{V}_{1}$ is Voltage of recived buse, $\mathrm{V}_{2}$ is voltage end bus, $\mathrm{X}$ is reactance, $\delta$ is power angle .From the above equations, it can be seen that voltage depends on the active power $\mathrm{P}$, while the power angle and frequency depends on the reactive power Q. However, this is contrary to the function of a high voltage network. Hence the traditional frequency droop control through active power and voltage droop control through reactive power may not function very well on low voltage network based microgrid. Instead, the voltage control should be implemented through active power and frequency control through reactive power generated in an inverter. The Microgrid can be based just on mainly resistive low voltage distribution systems lines. Thus the above mentioned control principles of voltage and frequency in high voltage network are not functional in low voltage systems based Microgrid [26]. 


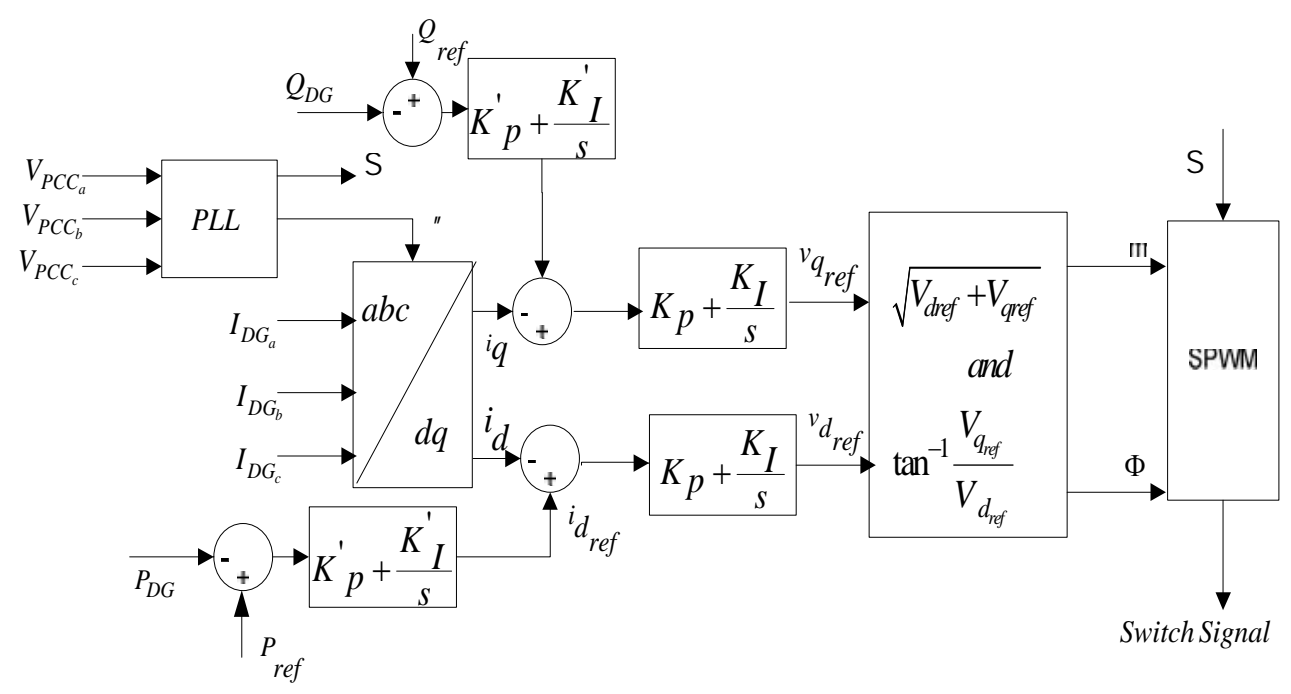

Fig.2. Inverter PQ control scheme

Based on the given set points for the active and reactive power Pref and $Q_{r e f}$, the power injected by the microgrid into the AC system can be controlled by a method that controls the time integral of the inverter output voltage space vector.

\section{B. constant power- voltage (PV) controlled inverter}

The block diagram shown in Fig. 3 presents a DG interface control where the DG provides voltage support. The voltage at the point of common coupling (PCC) is measured and is compared with a voltage reference value and is then applied to a PI controller to determine the modulation index amplitude value. In order to control the active power, the output active power of DG is measured and compared with the power reference value and the output is applied to a PI controller to determine the phase angle of the modulating waveform.

\section{C. constant current controlled inverter}

The block diagram shown in Fig 4 is designed to supply constant current output. A phase locked loop (PLL) is used to determine the frequency and angle reference $\theta$ of the PCC voltage. The abc current comonents are transformed using Park transformation to their dq components. The errors are applied to a PI controller to determine $\mathrm{I}_{\mathrm{dref}}$ and $\mathrm{I}_{\mathrm{qref}}$ of the inverter output current.

The $I_{d}$ current component controls the active power supplied by the DG, while $I_{q}$ controls the reactive power out of the DG. the output is applied to a PI controllers are then further processed as shown in fig. 3 to determine the phase angle of the modulating waveform. 


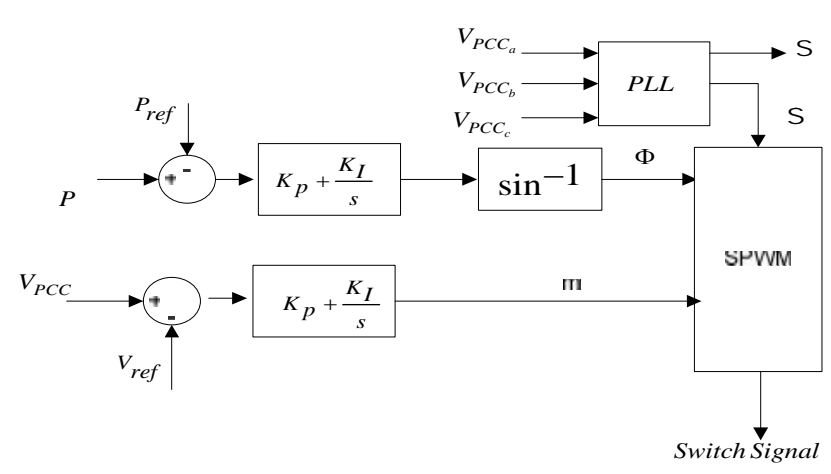

Fig.3. Inverter PV control scheme

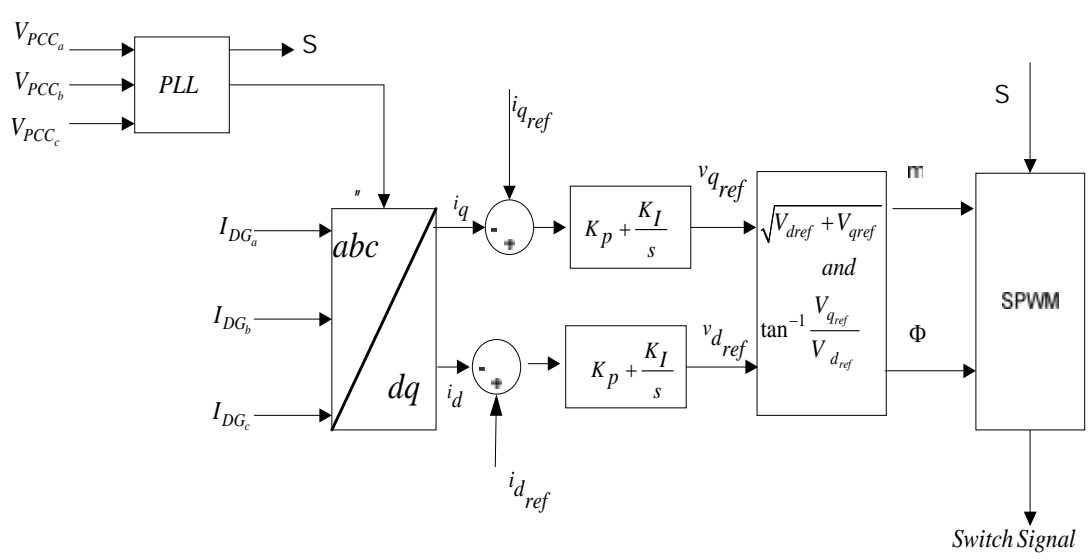

Fig.4. Inverter constant current control scheme

\section{Voltage-Frequency (VF) Control Scheme}

As its name suggests, in order developing a model for voltage-frequency controlled DG or in other words a reference DG, two control loops are needed. Voltage control loop is more or less the same as the one which previously developed for PV controlled DGS. Frequency controller can also be a PI controller which is driven by subtraction of system frequency from $50[\mathrm{~Hz}]$. As shown in Fig. 5, frequency of the system can be measured by a PLL, and in order to get a better performance, a feed-forward controller can be implemented.

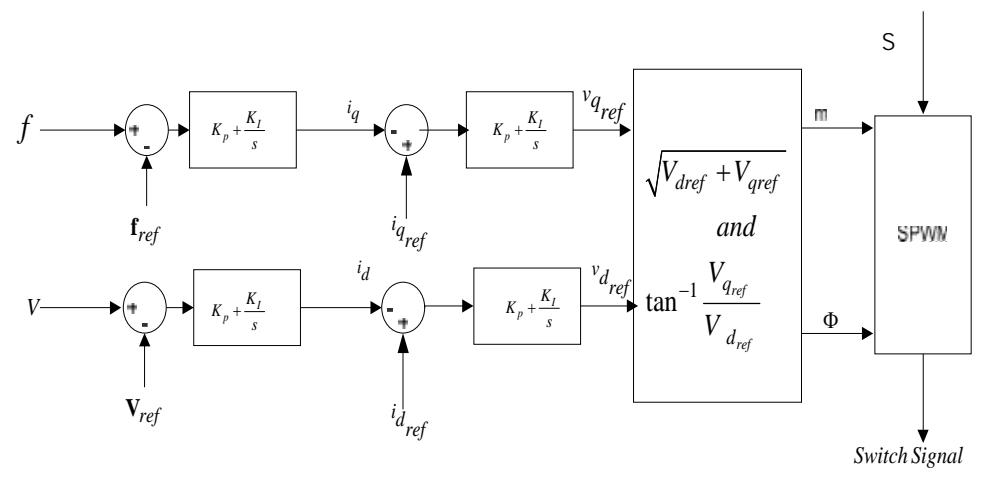

Fig.5. Inverter VF control scheme 


\section{SOLUTION METHODOLOGY}

In the next part shows the proposed scheme controller of a three phase grid connected voltage source inverter system. Fig. 6 shows the controller scheme topology consists of three main sections, GA algorithm, power controller and current controller for tuning of the controller coefficients. For more details, the following describe the operation of each section.

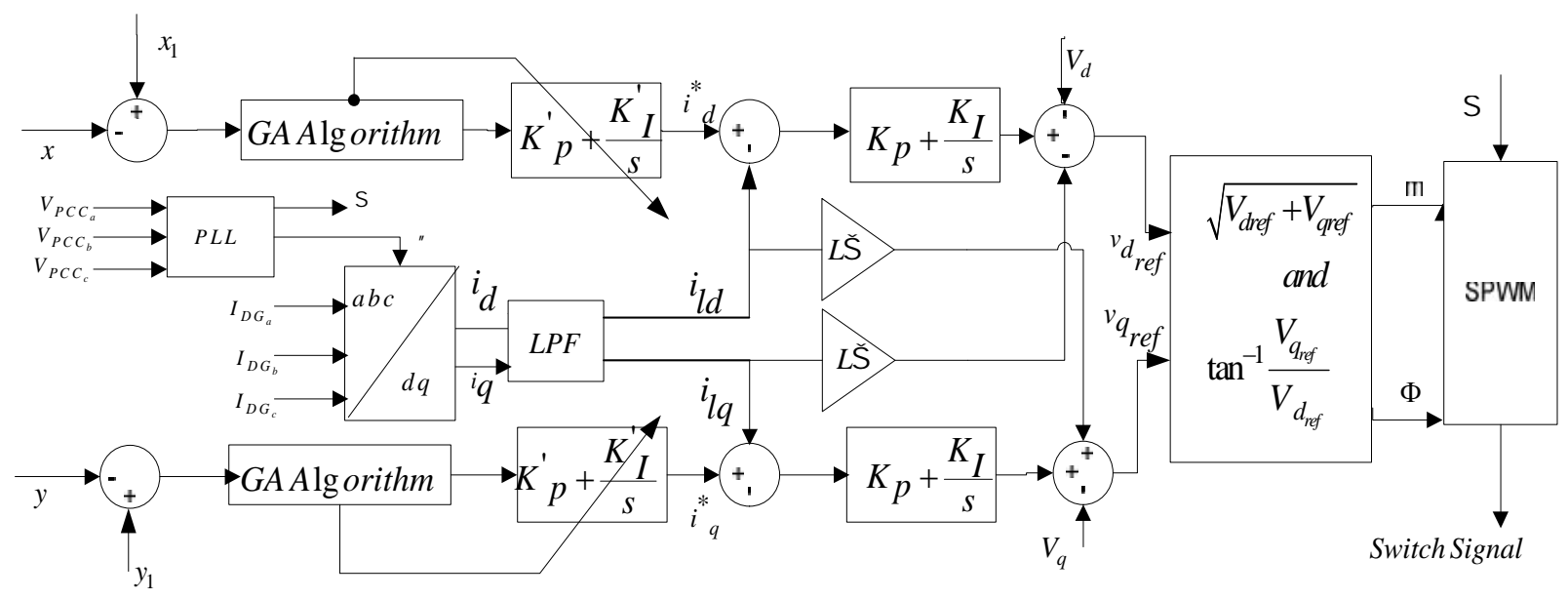

Fig.6. The proposed scheme controller

Details of the models proposed shown in Fig 6. This model combined from power control loop scheme and current control loop. The first section is power controller and other section shown current controller, that frequency of the system can be measured by a phase-locked loop (PLL). The PLL estimates the fundamental frequency and the phase angle based on the PCC voltage. This control strategy provides control over the inverter grid-side currents expressed in a local grid-side dq frame, which is defined at the PCC and rotates at the constant grid frequency. With respect to a stationary $a / 3$ frame, the local grid-side dq frame has a phase-angle difference of ${ }^{\theta}$, which is the estimated phase angle from the grid-side PLL unit. In this study, a genetic algorithm was proposed to improve the input control performance of the Microgrid, as presented in Fig 6. This optimization work consists of conventional PI controller, connected in series. In each of DGs used from this method, the $\mathrm{DG}_{1}$ controller has two input signals, namely, $\mathrm{x}$ and $\mathrm{y}$ that are voltage and frequency system respectively and other $\mathrm{DG}_{2}$ unit has two input signals that are active and reactive power. 


\section{A. Microgrid Voltage Control}

In a Microgrid, as the electrical distances are relatively small, the reactive power can be an sported from generators to the loads without a significant drop in the voltage. In any system the voltage at a bus is an important operating parameter which is required to be within certain limits. Various disturbances like line outages, load switching, line faults etc., leads to a drop in voltage at buses. The goal of Microgrid voltage control is to ensure that the voltage remains within the reference values by adjusting reactive power consumed or generated. A voltage controller is designed with the terminal voltages as input and compared with the reference voltage. The error voltage is filtered using a PI controller. The output of the voltage regulation control block gives the current that needs to be injected to maintain the terminal voltage according to droop set value.

\section{B. Microgrid Frequency Control}

The purpose of microgrid frequency control is to keep the frequency of the microgrid around the reference value. In a large power system, the generators have storage in their inertia. So, when a new load comes into the system, the frequency decreases slightly and the generator supports the load during the dynamic state. Whereas distributed generators have slow response and are almost inertia-less. So, it is important to design a microgrid along with the frequency controllers to provide some storage. Power versus frequency droop characteristics vary depending on the nature of the DG, and it is one of the critical microgrid performance curves. At the instant of islanding, the voltage phase angles at DG buses change, resulting in an apparent reduction in local frequency. This drop in frequencies of the DGs forces them to raise their power output and share the load proportionally.

\section{Objective Function}

For design of the genetic PI controller, we select controller gains $(K p, K i)$ from power controller as optimized control variables in the genetic algorithm. Fig. 7 the chromosome architecture of the GA for the gain tuning. In the evaluation procedure of GA algorithm, the integral of time absolute error of the basic value deviation of the Microgrid during islanded operation is selected as the performance index. Accordingly, the objective function $J$ is set by:

$$
\text { Minimize } J=\int_{0}^{t} t|\Delta e(t) d t|
$$




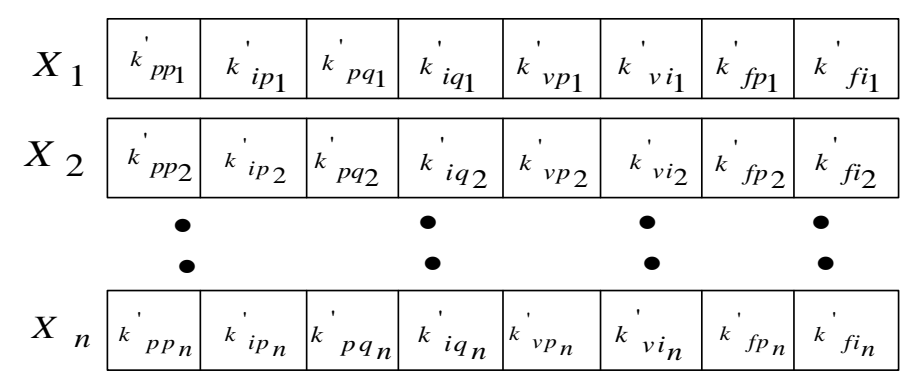

Fig.7. The chromosome architecture of the GA for the gain tuning

Where $t$ is simulation time and $e$ is the difference between the controlled signal and the reference value.

\section{GA Algorithm}

In a genetic algorithm, a population of candidate solutions (called individuals, creatures, or phenotypes) to an optimization problem is evolved toward better solutions. Each candidate solution has a set of properties (its chromosomes or genotype) which can be mutated and altered; traditionally, solutions are represented in binary as strings of $0 \mathrm{~s}$ and $1 \mathrm{~s}$, but other encodings are also possible. The evolution usually starts from a population of randomly generated individuals and happens in generations. In each generation, the fitness of every individual in the population is evaluated, the more fit individuals are stochastically selected from the current population, and each individual's genome is modified (recombined and possibly randomly mutated) to form a new population. The new population is then used in the next iteration of the algorithm.

Commonly, the algorithm terminates when either a maximum number of generations has been produced, or a satisfactory fitness level has been reached for the population.

The main property that makes these genetic representations convenient is that their parts are easily aligned due to their fixed size, which facilitates simple crossover operations [27]. The algorithm as shown in Fig.8 goes as follows.

Step 1: Represent the problem variable domain as a chromosome of fixed length; choose the size of the chromosome population $\mathrm{N}$, the simple Xover crossover and the mutation probability $\mathrm{Pm}$.

Step 2: Define a fitness function to measure the performance of an individual chromosome in the problem domain $(\mathrm{J})$. The fitness function establishes the basis for selecting chromosomes that will be mated during reproduction. 
Step 3: Randomly generate an initial population of size $\mathrm{N}$ that represent $\mathrm{N}$ initial candidate value of PI controller DG.

Step 4: Calculate the fitness of each individual chromosome.

Step 5: Select a pair of chromosomes for mating from the current population. Parent chromosomes are selected with a probability related to their fitness. High fit chromosomes have a higher probability of being selected for mating than less fit chromosomes.

Step 6: Create a pair of offspring chromosomes by applying the genetic operators.

Step 7: Place the created offspring chromosomes in the new population.

Step 8: Repeat Step 5 until the size of the new population equals that of initial population, N.

Step 9: Replace the initial (parent) chromosome population with the new (offspring) population.

Step 10: Go to Step 4, and repeat the process until the termination criterion is satisfied.

\section{CONFIGURATION OF A TEST SYSTEM}

Fig. 9 shows the configuration of a microgrid system for simulation. The test system consists of two DG units, electronic device, two distribution lines, and loads. The details of the test system are given in Table 2. A simulation platform under the Matlab environment was developed to evaluate the dynamic behavior of the microgrid. The upstream grid was modeled as an equivalent voltage source with the Thevenin impedance, and the load and distribution line were represented by constant impedance model, i.e., $R$ and $X$. the current control parameters are set to $\mathrm{Kp}=8.34$ and $\mathrm{Ki}=0.043$. The parameters of GA used for solving the problem presented in this work are furnished in Table 1 and the mutation probability is 0.01 .

\section{SIMULATION RESULTS}

Matlab simulation runs were made to validate the proposed genetic algorithm PI controller. The gain of conventional PI controller was determined by the GA algorithm under the island operating conditions. The optimization parameters of the GA algorithm are shown in Table 1. After tuning by GA algorithm, both controllers have optimized controller gains. The conventional PI controller applied to stabilize the frequency during transition mode under the condition with initial power flow of $50 \mathrm{~kW}$ from utility grid. A disconnect from the utility grid occurred at $t=0.01 \mathrm{~s}$ and the active load increased from $50 \mathrm{~kW}$ to $40 \mathrm{~kW}$ at $\mathrm{t}=0.5 \mathrm{~s}$. The frequency and power output of the microgrid after islanding are shown in Figure 10. The 
fuzzy PI controller greatly improved the control performance. The rising and settling time were reduced considerably.

Table 1. GA paramaters

\begin{tabular}{|c|c|c|c|c|}
\hline Pop.size & Selction & cross over & Mutation & Ter min ation \\
\hline 30 & $\begin{array}{c}\text { Nomalized } \\
\text { Geometric } \\
\text { Selection }\end{array}$ & Simple Xover & $\begin{array}{c}\text { Binary } \\
\text { Mutation }\end{array}$ & $\begin{array}{l}\text { Maximum } \\
\text { Number of } \\
\text { generation }\end{array}$ \\
\hline
\end{tabular}

Table 2. Details of the test microgrid system

\begin{tabular}{l|l}
\hline item & Description and Parameters \\
\hline System & $\begin{array}{l}\text { - DG unit: based inverter } \\
\text { - Loads: Constant impedance load } \\
\text { - Interconnection switch }\end{array}$ \\
\hline \multirow{2}{*}{ Inverter } & $\begin{array}{l}\text { Switch frequency }: 5 \mathrm{e}-6 \\
\text { Input DC voltage: } 250\end{array}$ \\
& $\begin{array}{l}\text { Filter I nductance }: 2.1 \mathrm{mH} \\
\text { DG output Power : }\end{array}$ \\
\hline \multirow{2}{*}{ Load } & $\begin{array}{l}\text { - Load } 1: 20 \mathrm{~kW}+\mathrm{j} 6 \mathrm{kvar} \\
\text { - Load } 2: 20 \mathrm{~kW}+j 6 \mathrm{kVar} \\
\text { - Load } 3: 10 \mathrm{~kW}+j 6 \mathrm{kVar}\end{array}$ \\
\hline \multirow{2}{*}{ Transformer } & $\begin{array}{l}3 \text {-phase } 22 . / 0.32 \mathrm{kV} 250 \mathrm{kVA} \\
\text { Leakage impedance } \% Z=6\end{array}$ \\
\hline Line Impedance & $\begin{array}{l}R_{I}=0.241 \Omega / \mathrm{km}, X_{1}=0.1 \Omega / \mathrm{km} \\
R_{2}=0.651 \Omega / \mathrm{km}, X_{2}=0.0912 \Omega / \mathrm{km}\end{array}$ \\
\hline
\end{tabular}




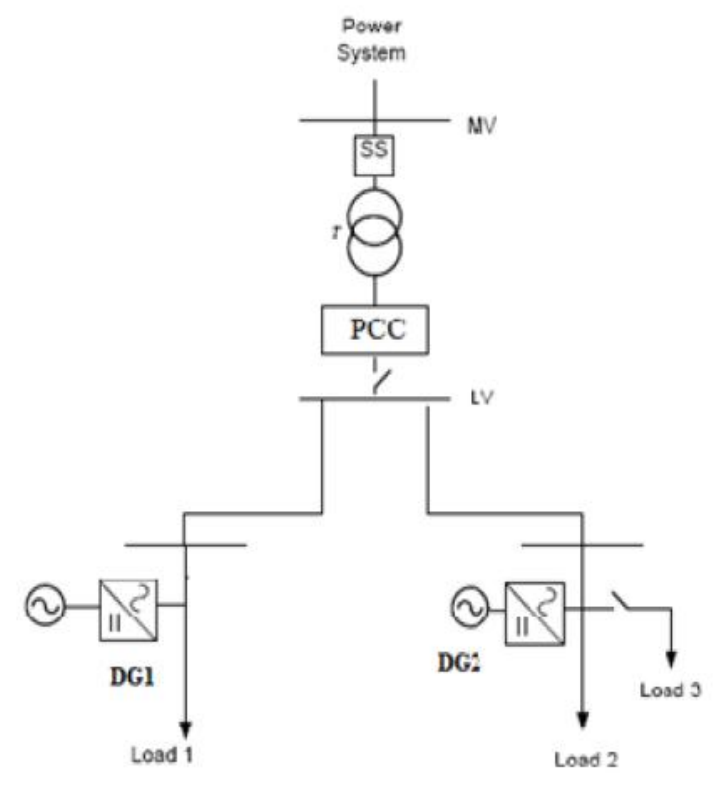

Fig. $y$ the configuration of a microgrid system
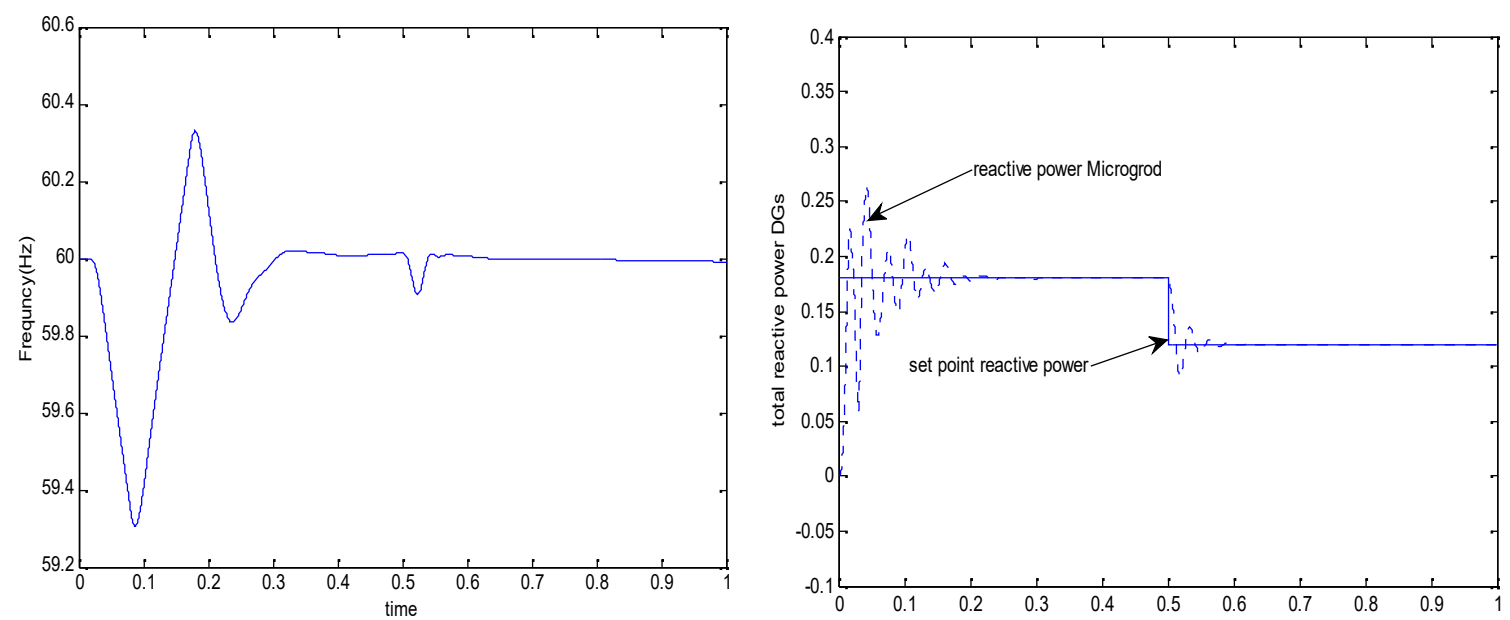

Fig.10. The microgrid frequency regulated by $V F$ controller Fig.11. The total reactive

power DGs and reactive load power 

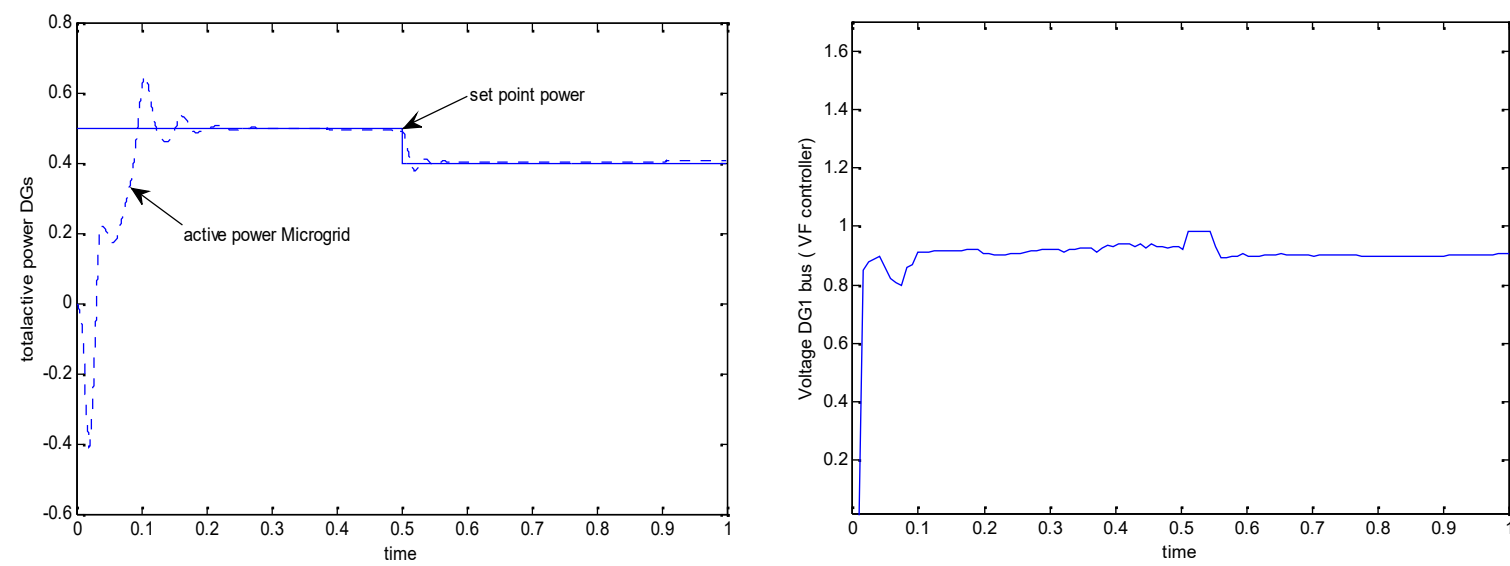

Fig.12. The total active power DGs Active load power Fig.13. The microgrid voltage regulated by Vf controller
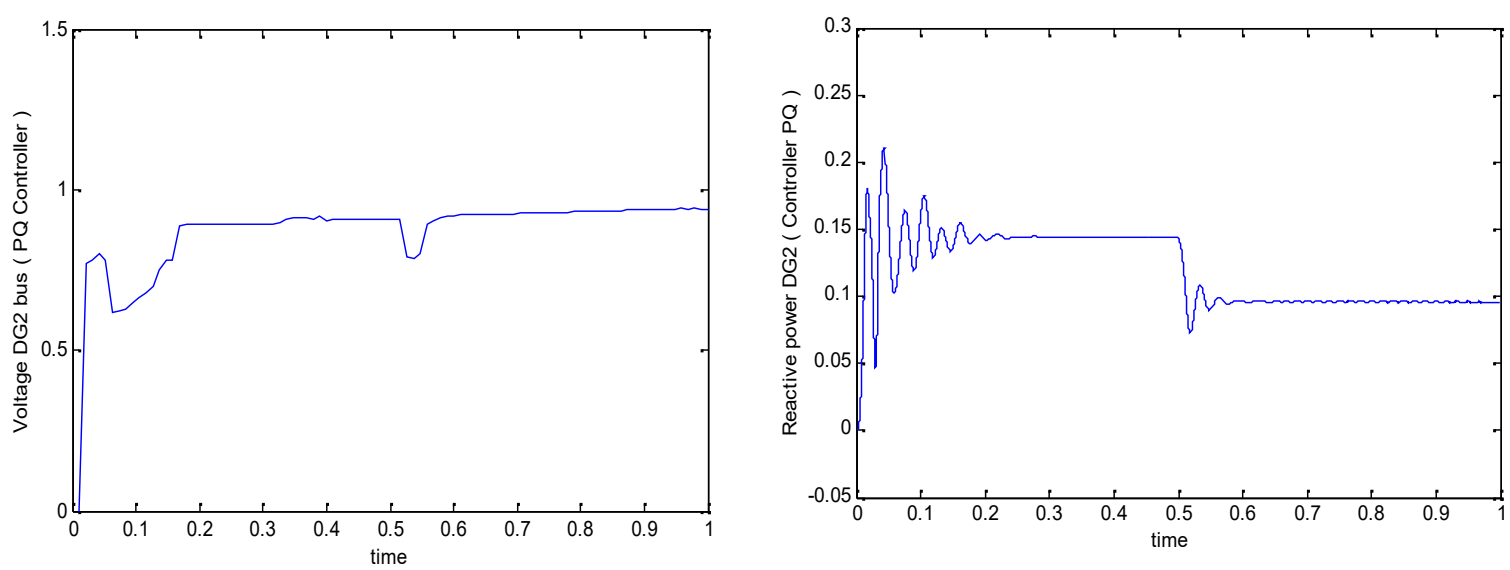

Fig.14. The microgrid voltage regulated by PQ controller

Fig.15. Reactive power generated by DG2 unit

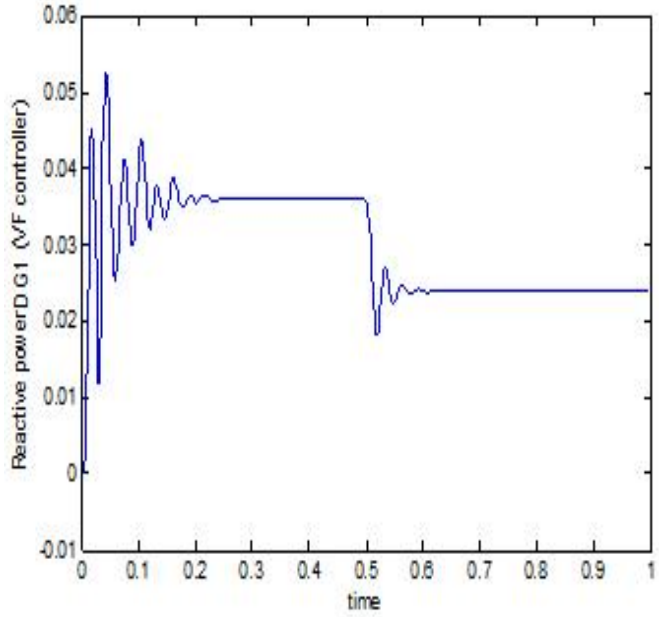

Fig.16. Reactive power generated by DG1 unit

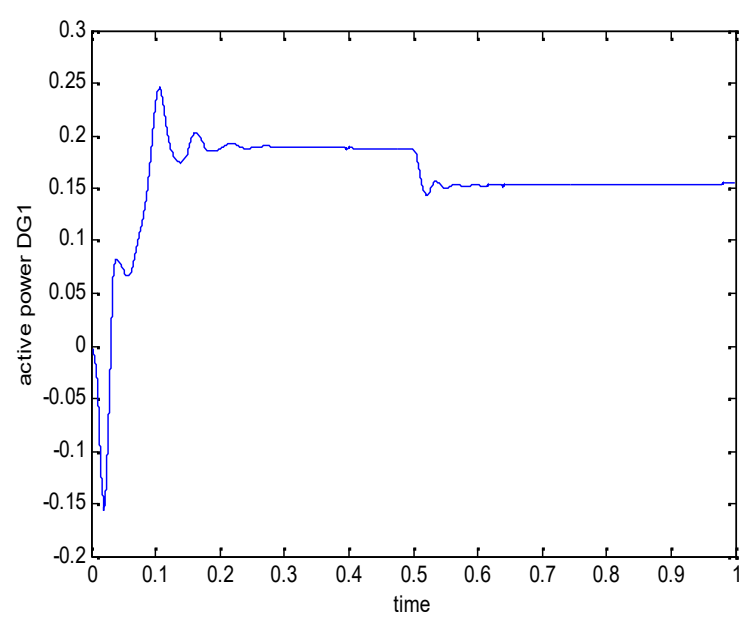

Fig.17. Active power generated by DG1 unit 


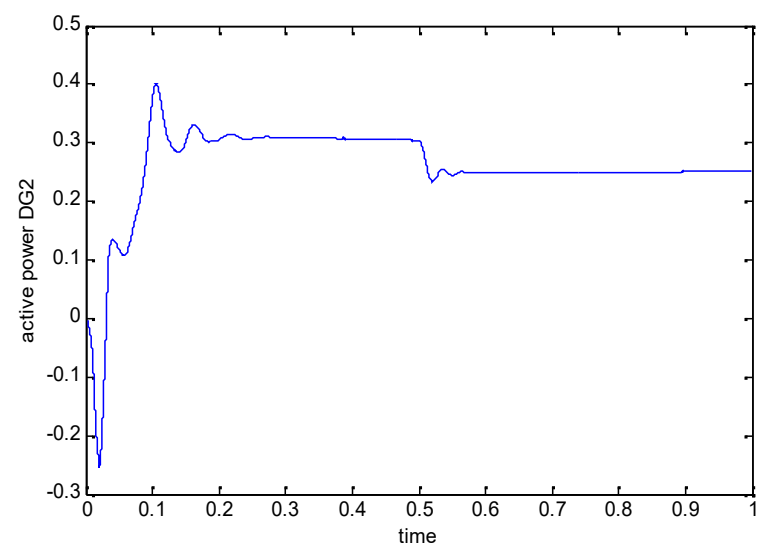

Fig.18. Active power generated by $\mathrm{DG}_{2}$ unit

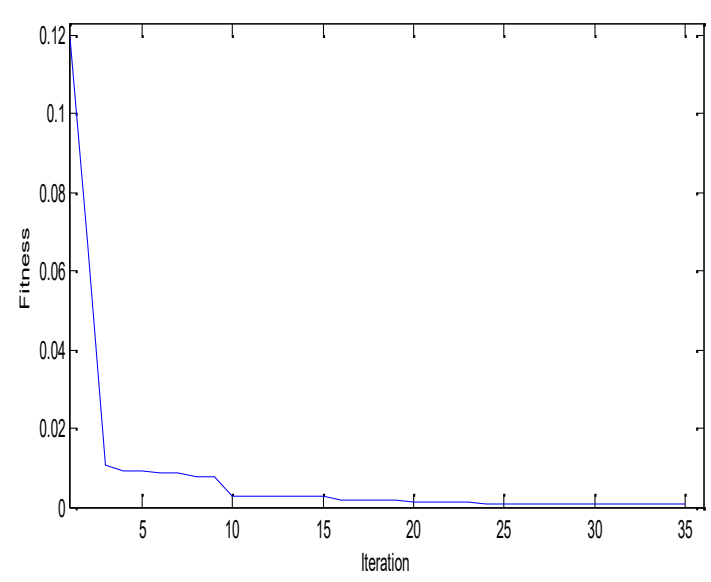

Fig.19. Fitness values of the frequency control objective

In figures 11 - 19 ,show the results of the simulation of islanding operation. Fig. 10 and Fig.13 show, the $V F$ controller which is adopted by the DG1 unit offers a good behavior and maintains the microgrid voltage even to 0.94(p.u.) and the frequency around 60, the frequency deviation was reduced considerably by the PI controller in comparison. Fig. 12 shows that at time step $\mathrm{t}=0.02$ the grid power is restricted. The DG units provide the required increase in generation while the controllable loads also participate also at time step $\mathrm{t}=0.5,0.33$ percent from load disconnected as a result of which the PQ controller DG reduces its Production to an acceptable maximum limit. Fig. 11 shows that, the reactive power compensation for both the DGs decrease to support the new reactive load at time 0.5 second also the reactive power had drawn from DGs at time 0.02 second the increases.Fig. 14 shows the sudden drop in voltage at the instant of load switching at the PQ controller DG2 but the sudden increase voltage at the $V F$ controller $\mathrm{DG}_{1}$ in the Fig.13. But the voltage recovers after total time of simulation is less 0.1 second. The behavior of the microgrid during the islanded mode with varying loads and power outputs of the DGs based inverter was evaluated. During the test period, the loads and power outputs of DGs were varied with time as shown in Fig 15, Fig 16, Fig 17 and Fig 18. the output active and reactive power of the $\mathrm{DG}_{2}$ unit almost are decreased to 0.28 p.u. and 0.091 p.u., respectively, while the output active and reactive power of the $\mathrm{DG}_{1}$ unit almost are decreased to 0.154 p.u. and 0.025 p.u., respectively. Both of the DGs unit good answered to disturbance load and tracked reference power that its show at Fig.11 and Fig.12.the PQ controller after disturbance reduced active and reactive power to make the balance between generation and demand. 
The $V F$ controller voltage and frequency after disturbance regulated. As shown in Fig 19, the result is related to the difference between set point and the computed value of controlled signal. The results show the populations finish their movement above the best positions, and the control parameters converge at optimum values which are shown in Table 3.

Table 3. Values control parameters

\begin{tabular}{|c|c|c|c|c|c|c|c|c|}
\hline Control & $\mathrm{K}_{\mathrm{pp}}$ & $\mathrm{k}_{\mathrm{ip}}$ & $\mathrm{k}_{\mathrm{pq}}$ & $\mathrm{k}_{\mathrm{iq}}$ & $\mathrm{k}_{\mathrm{vp}}$ & $\mathrm{k}_{\mathrm{vi}}$ & $\mathrm{k}_{\mathrm{fp}}$ & $\mathrm{k}_{\mathrm{fi}}$ \\
\hline \multicolumn{9}{|l|}{ Parameter } \\
\hline \multicolumn{9}{|l|}{ 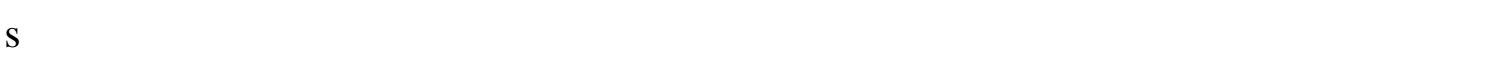 } \\
\hline \multirow[t]{2}{*}{ Values } & 0.78 & 15.2 & 0.168 & 105 & 0.3897 & -0.3658 & 0.900 & - \\
\hline & \multicolumn{4}{|c|}{0} & & & 4 & 0.9311 \\
\hline
\end{tabular}

\section{CONCLUSION}

The voltage and frequency of a microgrid may change quickly due to power unbalance between demand and supply during islanded operation. The power quality of microgrid during islanded operation is strongly related with the controller performance of DGs. Therefore a new optimal control strategy for distributed generation based inverter to connect to the generalized microgrid is proposed. In this paper GA is proposed for optimal coefficient PI controller problem on microgrid. The proposed method reduces the variety of the grid voltage along with the proper grid active as well as reactive power control. In this paper, two power control method were used for two DGs units. Models for voltage source inverter, its fundamental control schemes (PQ \& VF), were developed. These models that titled "PQ Controller DG”, "VF Controller DG” after verification of their performance were utilized for modeling an isolated power system. The gains of two controllers were tuned by the GA algorithm. As shown in the simulation results, the frequency and voltage deviations in islanded operation were reduced by the effective control action of the proposed PI controller.

\section{REFRENCES}

[1] Tsutomu T, Takao O, Tatsuya T. and Seiji T. Demonstration of Microgrid trough the activities toward halonic energy systems, in The 6th International Conference on Indoor 
Air Quality, Ventilation \& Energy Conservation in Buildings IAQVEC, Sendai, 2007, 16.

[2] Lasseter R. H and Paigi P. Microgrid: a conceptual solution, In Proc. IEEE Power Electronics Specialists Conference (PESC'04), June 2004, 4285-4290.

[3] Jardan R. K, Dranga O and Bereknyei D. Standby power supply using alternative energy through cogeneration technologies," In Proc. 3rd International Conference TELESCON Telecommunications Energy Special, 2000, 215-219.

[4] Katiraei F and Iravani M. R. Power management strategies for a microgrid with multiple distributed generation units," IEEE Transactions on Power Systems, 2006, 21, 18211831.

[5] Lopes J. A. P, Moreira C. L, and Madureira A. G. De ning control strategies for microgrids islanded operation," IEEE Transactions on Power Systems, 2006, 21, 916924.

[6] Chandorkar M. C, Divan D. M and Adapa R. Control of Parallel Connected inverters in standalone ac supply systems, IEEE Transactions on Industry Applications, vol. 29, no. 1, January/February 1993, 136-143.

[7] Guerrero J, De Vicuna L, Matas J, Castilla M, and Miret J. A wireless controller to enhance dynamic performance of parallel inverters in distributed generation system, IEEE Transactions on Power Electronics, 2004, 19(5), 1205-1213.

[8] Chiang S. J, Yen C. Y. and Chang K. T. A multimodule parallelable series-connected PWM voltage regulator, IEEE Transactions on Industrial Electronics, 2001, 48, 506-516.

[9] Borup U, Blaabjerg F and Enjeti P. Sharing of nonlinear load in parallel-connected threephase converters, IEEE Transactions on Industrial Applications, 2001, 37(6), 1817-1823.

[10]Robertr L, Akhil A, Chris M, John S, Jeff D, Ross G, Sakis A. S, Robert Y and Joe E. Integration of Distributed Energy Resources: The CERTS MicroGrid Concept, U.S. Department of Energy, White Paper LBNL-50829, 2002.

[11] Ramakumar R. Role of distributed generation in reinforcing the critical electric power infrastructure, in IEEE Power Engineering Society Winter Meeting, Columbus, 2001, 139-139.

[12] Bose S, Liu Y, Bahei-Eldin K, De Bedout J, and Adamiak M. Tieline controls in microgrid applications," in REP Symposium on Bulk Power System Dynamics and Control - VII, Charleston, 2007, 1-9. 
[13]Barbosa P. G, Rolim L. G, Watanabe E. H and Hanitsch R. Control stragy for gridconnected DC-AC converters with load power factor correction",IEE Proc. On Generation,Transmission and Distributions, 1998, 145(5), 487-491.

[14]Huang S and Pai F. Design and operation of grid-concted photovoltaic system with power-factor control and active islanding detection, IEE Proc. On Generation,Transmission and Distributions, 2001, 148(2), 243-250.

[15] Kashem M. A and Ledwich G. Distributed generation as voltage support for single wire earth return systems, IEE Transactions on power Delivery, 2004, 19(3), 1002-1011.

[16]Park S, II-Yop Chung, and Joon-Ho. Control Schemes of the inverter-interfaced multifunctional dispersed generation, IEEE Power Eengineering Society General Meeting, 2003, 3, 1924-1929.

[17]Wang T. C, Ye Z, Sinha G and Yuna X. Output filter design for a grid interconnected three phase inverter'IEEE $34^{\text {th }}$ Annual Power Electronics Specialist Conference,PESC,03,2003, 2, 779-784.

[18]Chen J. F, Chu C. L and Huang C. L. Combination voltage-controlled and curent controlled PWM inverters for UPS parallel operation, IEEE Trans. Power Electronics, 1995, 10, 547-558.

[19]Pogaku N, Prodanovic M and Green T. C. Modeling, Analysis and Testing of Autonomous Operation of an Inverter-Based Microgrid, IEEE Transactions on Power Electronics, 2007, 22(2), 613-615.

[20] Akbiyik B, Eksin I, Guzelkaya M, Yesil E. Evaluation of the performance of various fuzzy PID controller structures on benchmark systems, In Proceedings of the 4th International Conference on Electrical and Electronics Engineering (ELECO'2005), Bursa, Turkey, 2005. 388-393.

[21] Venkataramanan G and Illindala M. Small Signal Dynamics of Inverter Interfaced Distributed Generation in a Chain-Microgrid, in IEEE Power Engineering Society General Meeting, Tampa, 2007, 1-6.

[22] Pogaku N. Modeling, Analysis and Testing of Autonomous Operation of an InverterBased Microgrid, Power Electronics, IEEE Transactions on, March 2007, 613-625.

[23] Ramakumar R. Role of distributed generation in reinforcing the critical electric power infrastructure, in IEEE Power Engineering Society Winter Meeting, Columbus, 2001, 139-139. 
[24] Krishnamurthy S. Jahns T. M and Lasseter R. H. The Operation of Diesel Gensets in a CERTS Microgrid, in IEEE Power and Energy Society General Meeting - Conversion and Delivery of Electrical Energy in the 21st Century, Madison, 2008, 1-8.

[25] Yu Z, Zhenhua J, Xunwei Y. Small-signal modeling and analysis of parallelconnected voltage source inverters. In: IPEMC '09. IEEE 6th international power electronics and motion control conference; 2009, 377-383.

[26]Laaksonen H, Saari P and Komulainen R. Voltage and frequency control of inverter based weak LV network microgrid, in International Conference on Future Power Systems, Amsterdam, 2005, 1-6.

[27]Banzhaf, Wolfgang; Nordin, Peter; Keller, Robert; Francone, Frank. Genetic Programming - An Introduction. San Francisco, CA: Morgan Kaufmann. ISBN 978$1558605107,1998$.

\section{How to cite this article:}

Arefi F, Unesi H. S. and Ruzbehi S. Optimization of microgrids based on controller designing for islanded operation. J. Fundam. Appl. Sci., 2016, 8(2S), 191-210. 